\title{
Role of Lateral Hypothalamic Orexin (Hypocretin) Neurons in Alcohol Use and Abuse: Recent Advances
}

\author{
Leigh C. Walker ${ }^{1,2} \cdot$ Sarah Sulaiman Ch'ng ${ }^{1,2}$ - Andrew J. Lawrence ${ }^{1,2}$
}

Published online: 31 August 2016

(C) Springer International Publishing AG 2016

\begin{abstract}
Purpose of Review Alcohol use disorders (AUDs) are chronic relapsing disorders with the modest efficacy of current medications. The US Food and Drug Administration (FDA) and Japanese Pharmaceuticals and Medical Devices Agency (PMDA) approval of the dual orexin (OX) receptor antagonist, suvorexant for the treatment of insomnia, may enable repurposing of this drug for the treatment of other diseases. Here, we summarize and reflect on the most recent research on the role of OX neurons in alcohol use and abuse.

Recent Findings OX neurons regulate alcohol intake and seeking, although their involvement in different aspects of alcohol consumption/seeking, specific loci of action and interactions with other transmitter systems are still being clarified. Summary Recent studies have identified anatomic loci of action and interactions between $\mathrm{OX}$ and other neuropeptides that drive alcohol seeking. Future studies are required to fully elucidate these behaviors, in which optogenetic and chemogenetic approaches may prove useful.
\end{abstract}

Keywords Orexin $\cdot$ Hypocretin $\cdot$ Alcohol $\cdot$ Addiction · Lateral hypothalamus

This article is part of the Topical Collection on Neuropharmacology

Andrew J. Lawrence

andrew.lawrence@florey.edu.au

1 The Florey Institute of Neuroscience and Mental Health, Parkville, Victoria 3052, Australia

2 Florey Department of Neuroscience and Mental Health, The University of Melbourne, Parkville, Victoria 3010, Australia

\section{Introduction}

Alcohol use disorders (AUDs) are amongst the most common and devastating diseases in the world. Excessive alcohol use is the third leading risk factor for disease [1] and has physiological, psychological and social consequences on millions of individuals. AUDs have an annual prevalence of $\sim 10 \%$ and account for approximately $3.8 \%$ of deaths and $4.6 \%$ of disease and injury burden in developed countries [2]. Current pharmacological treatment of AUDs mostly involves altering the reinforcing effects of alcohol use. Three medications have been approved by the US Food and Drug Administration (FDA) specifically for the treatment of alcoholism: disulfiram (Antabuse ${ }^{\mathrm{TM}}$ ), naltrexone ( $\mathrm{ReVia}^{\mathrm{TM}}$ ) and acamprosate (Campral ${ }^{\mathrm{TM}}$ ). The effectiveness of all three treatments suffers pitfalls including limited efficacy, poor patient compliance and high relapse rates [3-5]. While new strategies and development of potential treatments for AUDs are ongoing, recent research has moved to a more efficient and economically feasible approach for drug development: the repurposing of other FDA approved drugs. Some examples include nalmefene, gabapentin, topiramate, baclofen, levetiracetam, quetiapine, aripiprazole and serotonin reuptake inhibitors (for full review see [6]). The orexin/hypocretin (OX) system presents a novel potential therapeutic target for preventing relapse to AUDs, with the recent FDA and Pharmaceuticals and Medical Devices Agency (PMDA) approval of the dual OX receptor antagonist (DORA) suvorexant (Belsomra ${ }^{\mathrm{TM}}$ ) for the treatment of insomnia. Suvorexant is currently involved in multiple stage $3 / 4$ clinical trials examining efficacy in sleep disorders, panic disorder, major depressive disorder, bipolar disorder, stress and cocaine use (https://clinicaltrials.gov). Other potential DORAs and single OX receptor antagonists (SORAs) are also in preclinical and clinical development and provide potential for the treatment of AUDs [7]. 
The hypothalamic OX neuropeptides were discovered and published independently in 1998 by two research groups [8, 9]. The OX system consists of two neuropeptides produced via enzymatic cleavage from prepro-OX, OX-A and OX-B and the two G-protein coupled receptors, the $\mathrm{OX}_{1}$ and $\mathrm{OX}_{2}$ receptors [10]. OX-A and OX-B are synthesized and produced exclusively in the dorsomedial $(\mathrm{DMH})$, perifornical $(\mathrm{PeF})$ and lateral (LH) regions of the hypothalamus. OX-A is a 33 amino-acid peptide, which binds and activates both $\mathrm{OX}_{1}$ and $\mathrm{OX}_{2}$ receptors with similar potencies, whereas OX-B, a 28 amino-acid peptide, is selective for $\mathrm{OX}_{2}$ receptors $[10,11]$. $\mathrm{OX}_{1}$ and $\mathrm{OX}_{2}$ receptors differ somewhat in their central expression profiles, and both subtypes can interact with $G_{q}, G_{s}$ and $\mathrm{G}_{\mathrm{i} / \mathrm{o}}$ [12]. OX neurons innervate regions implicated in arousal and drug abuse [13-15], suggesting a role for the OX system in reward seeking. In 2005, the Aston-Jones Laboratory provided such evidence by demonstrating that reinstatement of morphine place preference could be attenuated with a selective $\mathrm{OX}_{1}$ receptor antagonist [16]. These findings were expanded to voluntary drug self-administration, whereby central infusions of OX increased reinstatement of cocaine seeking in rats [17], while Lawrence et al. [18] provided the first evidence linking the OX system to alcohol selfadministration and cue-induced reinstatement of alcohol seeking [18]. Recent research in the field of OX neurobiology and pharmacology has given novel insights into the interaction of OX neurons with other systems in regulating alcohol-related behaviors. The utilization of small molecules (e.g. DORAs and SORAs) with different selectivity profiles targeting specific brain loci has broadened our understanding of the complexity of the OX system. This review focuses on recent research and discoveries made in the field of OX and alcohol abuse within the last 3 years (2014-2016).

\section{Role of Orexin Peptides in Alcohol Intake}

Orexigenic neuropeptides, such as OX, galanin (GAL) and enkephalin (ENK), generally promote alcohol drinking, although they may influence different aspects of this behavior. When injected into the paraventricular nucleus (PVN), OX $(0.9 \mathrm{nmol})$, GAL $(1.0 \mathrm{nmol})$ and the ENK analog D-Ala ${ }^{2}$ met-enkephalinamide (DALA) $(14.2 \mathrm{nmol})$ stimulated alcohol intake; however, their drinking patterns varied [19]. OX increased the number of drinking bouts within the first hour but did not influence the size or duration of the bout. GAL increased the size of drinking bouts, but not the number or duration while DALA increased both size and duration of bouts, but not the number. No change in food or water consumption was observed, showing these influences were solely on alcohol consumption under the experimental conditions employed. Therefore, the OX system may play a more important role in initiating alcohol drinking responses, while GAL and ENK act to sustain an already established drinking response. This could partly explain the efficacy of OX antagonists in preventing reinstatement of alcohol seeking and provide further support for targeting the OX system to prevent relapse.

\section{Role of Alcohol in Orexin System Expression/Activation}

Studies examining the role of alcohol consumption on hypothalamic OX activation and expression are ongoing. Moorman et al. [20] comprehensively examined the activation of OX neurons in male Sprague Dawley (SD) rats following different alcohol-seeking paradigms: home-cage seeking, ABA renewal and cue-induced relapse [20]. Home-cage alcohol seeking led to an increase in OX neuron activation in all subregions, and $\mathrm{OX} / \mathrm{Fos}$ double labeling was correlated with alcohol preference and number of alcohol bottle licks in the $\mathrm{PeF}$ and $\mathrm{LH}$, but not the DMH, suggesting that even when the more complex cognitive processes required in other alcoholseeking behaviors (such as cue- or context-induced reinstatement) are minimized, and no alcohol is consumed, OX activation still correlates with alcohol preference and seeking. In the ABA renewal model, animals are trained to self-administer a drug in one environment (A), the behaviors are extinguished in a different environment (B), and responding is reinstated when animals are placed back into the original environment (A). This models context-dependent relapse-like behavior. In agreement with previous studies [21], a correlation between active lever responding during ABA renewal and the percentage of OX/Fos double labeling was observed in the DMH and LH but not PeF. Interestingly, although cue-induced reinstatement led to a robust activation of OX neurons in all subregions of the hypothalamus, no correlation between active lever responses and the percentage of OX/Fos double labeling was observed. In line with this, a recent study in our lab has shown similarly that yohimbine-induced reinstatement of alcohol seeking causes a robust activation of OX neurons compared to alcohol naïve, vehicle- and yohimbine-treated alcohol-preferring (iP) rats but with no correlation between active lever responses and the percentage of OX/Fos double labeling [22]. Nevertheless, both cue- and yohimbine-induced reinstatement of alcohol seeking can be prevented with systemic administration of an $\mathrm{OX}_{1}$ receptor antagonist $[18,23]$. Overall, a strong relationship between alcohol seeking (in the absence of alcohol availability) and OX neuronal activation is clear. These results highlight the variable impact of specific subregions on alcohol seeking. However, further studies are required to examine the impact of activating specific neuronal ensembles and assessing effects on behavior. Contrastingly, a study examining the effects of OX in the sleep promoting effects of alcohol found a reduction in OX neuronal activation following intragastric alcohol administration in male SD rats [24]. This suggests the direct effects of alcohol on OX neurons 
may be inhibitory, while the motivational and contextual aspects of alcohol seeking lead to OX activation.

In the study by Kastman et al. [22], it is also interesting that yohimbine did not itself increase Fos expression in OX neurons. Although a low dose (1 mg/kg, i.p.) was administered, this dose is adequate to induce a robust reinstatement to alcohol and sucrose seeking [25]. Furthermore, although yohimbine does not seem to directly act upon OX neurons to precipitate relapse, systemic administration of the $\mathrm{OX}_{1}$ receptor antagonist SB-334867 attenuates yohimbine-induced reinstatement $[22,23]$. Therefore, yohimbine (at this dose) in combination with the alcohol-related context apparently increases stress reactivity and induces relapse. Indeed, it has been suggested that involvement of OX neurons in stress responses requires an interaction with the environment [26].

Recent studies have also examined the expression of OX peptide and receptors in the hypothalamus following bingelike alcohol consumption in mice. The drinking in the dark (DID) paradigm, in which water bottles are replaced with alcohol at the beginning of the dark cycle to promote high levels of alcohol consumption, caused a reduction in the number of OX-A positive neurons in the LH following one or three sessions of binge-like alcohol or sucrose consumption. In the $\mathrm{PeF}, \mathrm{OX}-\mathrm{A}$ expression was also reduced following three sessions of alcohol binge-like drinking [27], suggesting a reduction in the number of OX-A containing neurons immediately following reward consumption. The alteration in OX neuron numbers seems specific to reward consumption, with no differences seen in OX-A neuron number in rats with a past history of chronic alcohol consumption following alcohol seeking (without consumption) [22].

Another study examined OX messenger RNA (mRNA) expression in the PeF/LH and $\mathrm{OX}_{1}$ and $\mathrm{OX}_{2}$ mRNA expression in the paraventricular nucleus of the thalamus (PVT) following the two-bottle choice paradigm. Alcohol consumption led to an increase in $\mathrm{OX}_{2}$ but not $\mathrm{OX}_{1}$ receptor mRNA in the PVT and positively correlated with OX mRNA expression in the PeF/LH [28]. However, OX mRNA and peptide expression in the LH do not necessarily correlate. Olney et al. [27] found that in the presence of alcohol, OX mRNA within the LH was increased, while OX peptide expression was decreased. This increase in OX mRNA may be produced in response to OX release [27]. In the LH, four daily DID sessions of saccharin, but not alcohol, reduced $\mathrm{OX}_{1}$ receptor mRNA expression of C57BL/6J mice [29]. The authors hypothesized that receptor down regulation may act as a protective mechanism, preventing escalating overconsumption, as observed with saccharin consumption. Therefore, an inability to properly reduce $\mathrm{OX}$ autoreceptors that might modulate alcohol-induced OX synthesis could actually facilitate vulnerability to overconsumption and binge-like alcohol consumption over time. However, with only a small sample size $(n=3)$, this requires further elucidation.
Recently, a model of voluntary alcohol intake has been developed in zebrafish [30]. Zebrafish were presented with a gelatin-alcohol mixture and readily consumed stable levels of a 10 or $20 \%$ alcohol-gelatin mixture reaching relevant blood alcohol concentrations (BECs). This model was used to examine alcohol intake on various behaviors including aggression, anxiety and locomotion and furthermore to characterize the effects of OX and GAL on alcohol consumption. Intake of alcohol-gelatin increased locomotion, reduced anxiety and stimulated aggressive behavior while increasing expression of OX and GAL in hypothalamic areas [30]. Furthermore, using this model, they examined the impact of embryonic alcohol exposure on hypothalamic neurogenesis, expression of orexigenic neuropeptides, voluntary alcohol consumption, locomotor behaviors and effects of central OX-A injections on these alcohol-related behaviors [31]. Embryonic alcohol exposure $(0.25$ and $0.5 \%, 2 \mathrm{~h})$ dose-dependently increased hypothalamic neurogenesis of OX neurons and OX expression in the anterior hypothalamus. These changes were accompanied by an increase in voluntary consumption of $10 \%$ alcohol-gelatin and in novelty-induced locomotor and exploratory behavior in adult zebrafish and locomotor activity in larvae. Intra-cerebroventricular (i.c.v.) injection of OX-A stimulated novelty-induced locomotor behavior while also increasing intake of food and alcohol equally. These findings suggest alcohol-induced increases in neurogenesis and expression of OX peptides contribute to the behavioral changes induced by embryonic exposure to alcohol in zebrafish [31]. The similarity of findings in zebrafish and rodent models give validity for this model to be used as a screening tool to investigate genetic manipulations in controlling alcohol intake [30]. The greater genetic control afforded by zebrafish models allows single-gene mutations to be introduced into the OX system to characterize its role in alcohol use in a more refined manner.

Few studies have examined the interaction of $\mathrm{OX}$ and alcohol in humans. Recently, a clinical study assessed the blood concentration of OX in 32 male patients with alcohol dependence and 23 healthy males. Alcohol-dependent patients showed increased OX blood concentration compared to the control group at the onset of the study. Furthermore, patients with greater severity of alcohol dependence (Short Alcohol Dependence Data [SADD] score range, 20-45) had a greater OX blood concentration than those with lesser severity of alcohol dependence (SADD score range: 10-19). After 4 weeks of abstinence, OX blood levels were reduced and no different than healthy controls [32]. Therefore, while OX receptors are promising targets in the treatment of alcohol relapse prevention, blood OX concentration may be a useful prognostic marker to determine the risk of alcohol relapse, although replication of the current data are necessary.

These studies have provided further evidence for the involvement of the OX system in alcohol-related behaviors. 
OX neurons are activated by a variety of alcohol-seeking behaviors in rats, including home-cage alcohol seeking, cueinduced alcohol reinstatement, ABA renewal and stressinduced alcohol seeking [22, 20]. In contrast, acute alcohol consumption was associated with a decrease in OX neuron activation, showing a distinction between the motivational properties of alcohol seeking and acute alcohol consumption $[22,20,24]$. Indeed, others have hypothesized OX is not specifically involved in reward seeking, or other behaviors, but has a unified underlying role in motivation. Evidence shows that OX role in many behaviors (including reward-associated behaviors) is conditional and dependent on the motivational state of the animal; however, further research is required to further test this theory (for full review see [33]). The specific involvement of distinct hypothalamic subregions in relation to alcohol seeking is somewhat ambiguous and may differ across behavioral paradigms $[22,20]$. The number of OX positive neurons does not appear to be regulated by seeking behaviors $[22,20]$ but is altered following acute reward consumption and may be specific to the PeF and LH [27]. Furthermore, OX receptor mRNA alterations were seen following alcohol consumption [28]. While a decrease in $\mathrm{OX}_{1}$ mRNA in the LH may reflect the loss of autoregulation and facilitate excess alcohol consumption, increased $\mathrm{OX}_{2}$ mRNA in the PVT indicates this may be another brain region where $\mathrm{OX}$ regulates alcohol consumption. An issue plaguing the ability to generalize across studies is the discrepancy in boundary definitions between the DMH, PeF and LH, which may contribute to the differences reported in subregion contribution. Further characterization of the neurochemical phenotypes and connectivity of discrete OX subpopulations will help to parse out their distinct roles in alcohol-related behaviors.

\section{Peripheral and Central OX Receptor Targeting}

While both $\mathrm{OX}_{1}$ and $\mathrm{OX}_{2}$ receptors are involved in alcohol consumption and seeking, their distinct roles in specific alcohol-related behaviors remain somewhat unclear. A recent study comprehensively examined the individual and combined role of these receptors in different alcohol selfadministration paradigms utilizing the $\mathrm{OX}_{1}$ receptor antagonist, SB-334867, the $\mathrm{OX}_{2}$ receptor antagonist, LSN2424100, and the DORA almorexant [34]. The behaviors measured were voluntary home-cage alcohol consumption in the twobottle choice paradigm, motivation to seek alcohol in the operant progressive ratio (PR) responding and binge-like alcohol consumption in the DID paradigm. SB-334867 (10 or $30 \mathrm{mg} / \mathrm{kg}$, i.p.) attenuated alcohol consumption in female iP rats in the two-bottle choice paradigm; however, LSN2424100 (10 or $30 \mathrm{mg} / \mathrm{kg}$, i.p.) had no effect. Almorexant (100 mg/kg, i.p.) also attenuated alcohol consumption; however, at this dose, water consumption was also reduced, suggesting non-specific effects. SB-334867 had no effect on PR lever responses for alcohol, alcohol selfadministration or breakpoint; however, LSN2424100 $(30 \mathrm{mg} / \mathrm{kg}$, i.p.) reduced active lever responses, alcohol selfadministration and breakpoint. Almorexant (10, 30 and $60 \mathrm{mg} / \mathrm{kg}$, i.p.) also reduced active lever responses in alcohol self-administration and breakpoint. Furthermore, the inactive enantiomer of almorexant did not suppress breakpoints or alcohol self-administration in rats, indicating that the effect was specific to antagonism of $\mathrm{OX}_{1}$ and $\mathrm{OX}_{2}$ receptors. In the DID paradigm, SB-334867 (30 mg/kg, i.p.) and LSN2424100 (60 mg/kg, i.p.) reduced binge alcohol consumption in male C57BL6/J mice and corresponding BECs; however, this dose also reduced $1 \%$ sucrose consumption. Almorexant (100 mg/kg, i.p.) also reduced binge alcohol consumption and corresponding BECs, without reducing $1 \%$ sucrose consumption [34].

Also utilizing the DID paradigm, another study examined lower doses of the $\mathrm{OX}_{1}$ antagonist SB-334867 (5, $10 \mathrm{mg} / \mathrm{kg}$, i.p.) in $\mathrm{C} 57 \mathrm{BL} / 6 \mathrm{~J}$ mice [29]. A dose-related reduction was observed in the first hour of alcohol consumption, but no reduction was seen $2 \mathrm{~h}$ after administration relative to controls. SB-334867 (10 mg/kg, i.p.) did not alter locomotor activity but did reduce binge-like consumption of saccharin [27]. These findings suggest a role for $\mathrm{OX}$ in processing the salience of rewards in general in binge paradigms. Furthermore, saccharin is a non-caloric reward, suggesting this effect is not impacted upon by caloric reinforcement. The doses at which SB-334867 blunted alcohol consumption in the study by Olney and colleagues differ from those of Anderson et al. [34] with only the $30 \mathrm{mg} / \mathrm{kg}$ dose of SB334867 having any effect. Central administration of SB334867 ( $3 \mu \mathrm{g} / \mu \mathrm{L}$, i.c.v.) has also been assessed in the DID paradigm [29]. This dose attenuated alcohol consumption and corresponding BECs but not $0.15 \%$ saccharin or food consumption, suggesting that the discrepancies seen by Olney et al. [27] may be due to procedural differences, peripheral interactions or dosage effects. Indeed, some variability in dose responses and potential negative findings (summarized in Table 1) may relate to different formulations of SB-334867, some of which suffer from hydrolytic instability [35] and potential off-target effects [36].

An alternative selective $\mathrm{OX}_{1}$ receptor antagonist GSK1059865 was used to examine the effects of OX recep- $_{1}$ tors in alcohol consumption specifically in alcohol-dependent mice. Mice were rendered ethanol dependent by exposure to chronic intermittent alcohol (CIE) in inhalation chambers (16 h/day for 4 days). Alcohol-dependent mice administered with GSK1059865 (10-50 mg/kg, i.p.) showed a dosedependent decrease in alcohol consumption, while airexposed mice only decreased drinking at the highest dose. $\mathrm{OX}_{1}$ receptor antagonism was specific to the effects of alcohol, with no decreases in sucrose consumption observed [37]. Furthermore, a recent study failed to see an attenuation of 
Table 1 Role of $\mathrm{OX}_{1 / 2}$ receptors in alcohol seeking

\begin{tabular}{|c|c|c|c|c|c|c|}
\hline Antagonist & Dose & Region & Species & Paradigm & Outcome & Reference \\
\hline \multicolumn{7}{|l|}{$\mathrm{OX}_{1}$} \\
\hline \multirow[t]{16}{*}{ SB-334867 } & $10,30 \mathrm{mg} / \mathrm{kg}$ & Peripheral & Female iP rat & Two-bottle choice & Reduction & {$[34]$} \\
\hline & $10,30 \mathrm{mg} / \mathrm{kg}$ & Peripheral & Female iP rat & Progressive ratio & No effect & \\
\hline & $30 \mathrm{mg} / \mathrm{kg}$ & Peripheral & Male C57BL6/J mice & Drinking in the dark & Reduced & \\
\hline & $5,10 \mathrm{mg} / \mathrm{kg}$ & Peripheral & Male C57BL6/J mice & Drinking in the dark & Reduced $^{\mathrm{a}}$ & {$[27]$} \\
\hline & $3,10 \mathrm{mg} / \mathrm{kg}$ & Peripheral & Male C57BL6/J mice & Two-bottle choice & No effect & [38] \\
\hline & $3 \mathrm{mg} / \mathrm{kg}$ & Peripheral & Male C57BL6/J mice & Two-bottle choice with quinine & Reduced & \\
\hline & $3 \mu \mathrm{g} / \mathrm{ul}$ & Central & Male C57BL6/J mice & Drinking in the dark & Reduced & [29] \\
\hline & $6 \mu \mathrm{g} / \mathrm{side}$ & Intra-NAc & Male Wistar & Two-bottle choice & Reduced $^{\mathrm{a}}$ & {$[56]$} \\
\hline & $3 \mu \mathrm{g} /$ side & Intra-PL & Male iP rat & Cue-induced reinstatement & Reduced & [59] \\
\hline & $3 \mu \mathrm{g} / \mathrm{side}$ & Intra-VTA & Male iP rat & Cue-induced reinstatement & Reduced & \\
\hline & $0.25 \mathrm{nmol} / \mathrm{side}$ & Intra-PVN & Male Wistar & Cue-induced reinstatement & Reduced & {$[60]$} \\
\hline & $0.25 \mathrm{nmol} / \mathrm{side}$ & Intra-BNST & Male Wistar & Cue-induced reinstatement & Reduced & \\
\hline & $0.25 \mathrm{nmol} / \mathrm{side}$ & Intra-VTA & Male Wistar & Cue-induced reinstatement & No effect & \\
\hline & $0.25 \mathrm{nmol} / \mathrm{side}$ & Intra-LC & Male Wistar & Cue-induced reinstatement & No effect & \\
\hline & $10 \mathrm{nmol} / \mathrm{side}$ & Intra-aPVT & Male Long-Evans rat & Two-bottle choice & No effect & {$[28]$} \\
\hline & $3 \mu \mathrm{g} /$ side & Intra-NI & Male iP rat & Yohimbine-induced reinstatement & No effect & [22] \\
\hline GSK1059865 & $10-50 \mathrm{mg} / \mathrm{kg}$ & Peripheral & Male C57BL6/J mice & CIE + Two-bottle choice & Reduced & [37] \\
\hline \multicolumn{7}{|l|}{$\mathrm{OX}_{2}$} \\
\hline \multirow[t]{3}{*}{ LSN2424100 } & $10,30 \mathrm{mg} / \mathrm{kg}$ & Peripheral & Female iP rat & Two-bottle choice & No effect & {$[34]$} \\
\hline & $30 \mathrm{mg} / \mathrm{kg}$ & Peripheral & Female iP rat & Progressive ratio & Reduced & \\
\hline & $60 \mathrm{mg} / \mathrm{kg}$ & Peripheral & Male C57BL6/J mice & Drinking in the dark & Reduced $^{\mathrm{a}}$ & \\
\hline \multirow[t]{4}{*}{ TCS-OX2-29 } & $3,10 \mathrm{mg} / \mathrm{kg}$ & Peripheral & Male C57BL6/J mice & Two-bottle choice & No effect & [38] \\
\hline & $3,10 \mathrm{mg} / \mathrm{kg}$ & Peripheral & Male C57BL6/J mice & Two-bottle choice with quinine & No effect & \\
\hline & $10 \mathrm{nmol} / \mathrm{side}$ & Intra-aPVT & Male Long-Evans rat & Two-bottle choice & Reduced & {$[28]$} \\
\hline & $100 \mu \mathrm{g} / \mathrm{side}$ & Intra-NI & Male iP rat & Yohimbine-induced reinstatement & Reduced & {$[22]$} \\
\hline \multicolumn{7}{|l|}{ DORA } \\
\hline \multirow[t]{3}{*}{ Almorexant } & $100 \mathrm{mg} / \mathrm{kg}$ & Peripheral & Female iP rat & Two-bottle choice & Reduced $^{\mathrm{a}}$ & {$[34]$} \\
\hline & $10-60 \mathrm{mg} / \mathrm{kg}$ & Peripheral & Female iP rat & Progressive ratio & Reduced & \\
\hline & $100 \mathrm{mg} / \mathrm{kg}$ & Peripheral & Male C57BL6/J mice & Drinking in the dark & Reduced & \\
\hline
\end{tabular}

${ }^{\text {a }}$ Off-target effect on natural reward or water consumption reported

alcohol consumption in C57BL/6 mice following SB-334867 administration (3,10 $\mathrm{mg} / \mathrm{kg}$ i.p.). However, in the same study, SB-334867 (3 mg/kg i.p.) was sufficient to reduce compulsive-like alcohol responding, in which aversively tasting quinine $(100 \mu \mathrm{M})$ was added [38]. This provides further evidence that OX receptor antagonism is more effective in rodent models of excessive consumption and high motivation [39] and therefore may provide a useful intervention target for disorders such as addiction, including AUDs, where drug/alcohol motivation is strongly elevated and compulsive-like behaviors are observed.

Overall, the data reported within the previous 3 years complement and extend previous literature reports demonstrating involvement of OX receptors in alcohol consumption and seeking. In the central nervous system, both OX receptor mRNAs are expressed in regions that receive dense OX innervations. $\mathrm{OX}_{1}$ and $\mathrm{OX}_{2}$ receptor mRNA expressions show partial overlap but largely distinct and complementary distribution patterns. This, in combination with the knowledge that $\mathrm{OX}_{1}$ and $\mathrm{OX}_{2}$ have the potential to signal via different pathways, suggests that each receptor subtype plays different physiological roles $[12,40]$. $\mathrm{OX}_{1}$ receptor antagonists reduced both binge-like alcohol consumption and voluntary homecage consumption. However, no reduction in operant PR responding was observed in female iP rats, suggesting the $\mathrm{OX}_{1}$ receptor involvement in consummatory behavior but not motivation to seek alcohol. In contrast, $\mathrm{OX}_{2}$ receptor antagonism reduced binge-like consumption and operant PR responding for alcohol but not voluntary unlimited access alcohol consumption. Thus, $\mathrm{OX}_{2}$ signaling may be more involved in modulating the motivational circuits underlying alcohol seeking as opposed to directly regulating alcohol 
reward. However, this is a generalization of a complex behavior and while pharmacological manipulations offer insight into the mechanisms of action, the variability between species, gender and procedure hinder interpretation. For example, although no difference was seen in the breakpoint of PR responding in female iP rats following SB-334867 administration [34], a lower dose was sufficient to decrease the motivational effects in male iP rats [41]. As with many fields, most studies to date have been carried out in male animals. The study by Anderson et al. [34] is one of few that examine the role of the OX system in alcohol consumption and seeking in female rats [34]. Further studies are required to elucidate whether other gender differences exist specific to alcoholrelated behaviors, as there are known differences with other drugs of abuse following SB-334867 administration [42].

The OX system is implicated in numerous physiological functions, including feeding [9], motivation [43], sleep/ wakefulness [44], female proestrus [45, 46] and male sexual behavior [47]. This creates the possibility of a variety of ontarget side effects following chronic medication. To be effective, the therapeutic targeting of this system must also be selective, avoiding potential off-target effects. In this regard, suvorexant has an excellent safety profile which has enabled FDA approval. Although less potent than other DORAs, suvorexant has a high selectivity for OX receptors over other receptors, ion channels and enzymes [46]. However, some additive negative psychomotor effects were seen in healthy male patients given suvorexant and alcohol in combination [48], raising some concerns about the sedative effects of OX receptor antagonism.

Little is known about the molecular consequences of repeated administration of OX receptor antagonists. Studies indicate a limited profile of chronic DORA and SORA tolerance [49]. However, repeated SB-334867 administration prior to extinction training led to higher responding in the subsequent cue-induced reinstatement session for cocaine seeking when no SB-334867 was administered [50]. Similar studies are required in the alcohol field. Furthermore, studies suggest that downregulation of the OX system is associated with depressive-like symptoms [51-53], raising concerns about the long-term administration of OX receptor antagonists. However, the depressive behavior has not been observed in clinical trials reported to date.

\section{OX Loci-Specific Targeting}

Studies discussed in the previous section gave valuable insight into the broad involvement of OX receptors in alcohol-related behaviors. Nevertheless, more recent studies have looked at discrete effects of OX receptor agonism and/or antagonism to ascertain the specific brain regions involved in these behaviors (Fig. 1). Mayannavar and colleagues examined the impact of intra-nucleus accumbens (NAc), infusion of OX-A (100 and
$250 \mathrm{pmol}$ ) on feeding behavior and alcohol consumption in male Wistar albino rats. OX-A infusion into the NAc dosedependently increased both food and $10 \%$ alcohol consumption but not alcohol preference in the two-bottle choice paradigm [54]. This study is in line with previous reports that intraNAc core infusion of the $\mathrm{OX}_{2}$ receptor antagonist TCS-OX229 reduces alcohol self-administration [55]. To elucidate which receptor was involved, SB-334867 (6 ng) was administered intra-NAc. Decreases in $10 \%$ alcohol consumption were observed $1 \mathrm{~h}$ post infusion; however, decreases in water and food intake were also observed [56].

The role of OX in alcohol consumption was also recently examined in the PVT. This region has previously been implicated in alcohol seeking [57], receives dense OX innervation [14] and expresses $\mathrm{OX}_{1}$ and $\mathrm{OX}_{2}$ receptors [58]. Male LongEvans rats underwent an intermittent access two-bottle choice paradigm or oral gavage before examination of Fos expression in the PVT [28]. Both groups showed increased neuronal activation in the anterior PVT (aPVT), suggesting that this sitespecific effect was due to alcohol exposure. Moreover, alcohol consumption positively correlated with $\mathrm{OX}_{2}$, but not $\mathrm{OX}_{1}$ receptor mRNA in the aPVT, but not posterior PVT (pPVT). Additionally, alcohol gavage increased double labeling of Fos with $\mathrm{OX}_{2}$ but not $\mathrm{OX}_{1}$, specifically in the aPVT. Increased alcohol intake was observed following local microinjections of OX-A and OX-B (1 nmol) into the aPVT but not pPVT. Furthermore, TCS-OX2-29 (10 nmol) but not SB-334867 $(10 \mathrm{nmol})$ reduced alcohol consumption. These effects were specific to alcohol consumption, with no alteration in sucrose or food consumption. The authors proposed that the aPVT shows a positive feedback relationship with alcohol drinking, whereby alcohol consumption induces hypothalamic OX to act in the aPVT at $\mathrm{OX}_{2}$, stimulating neurons in the aPVT that further perpetuates the alcohol drinking cycle [28].

Recent literature also provides evidence for the involvement of $\mathrm{OX}_{1}$ signaling in the ventral tegmental area (VTA) and prelimbic cortex (PL) in cue-induced alcohol seeking [59]. Bilateral infusions of the $\mathrm{OX}_{1}$ receptor antagonist SB$334867(3 \mu \mathrm{g} / \mathrm{side})$ into the VTA and PL attenuated cueinduced reinstatement of alcohol seeking in iP rats. Furthermore, in the PL, no effect was observed in cueinduced sucrose seeking, suggesting the effect seen in this region is specific to alcohol and not natural reward seeking. In addition, Ubaldi et al. (2016) have implicated the PVN and bed nucleus of the stria terminalis (BNST) in OX-mediated cue-induced reinstatement of alcohol seeking [60]. Previous research has shown the ability of neuropeptide S (NPS) to facilitate relapse to alcohol seeking mediated by the OX system [61]. Using intra-hypothalamic NPS injections to facilitate cue-induced reinstatement, the authors targeted specific regions of $\mathrm{OX}$ innervation and determined their contribution to cue-induced reinstatement. Microinjections of SB-334867 (5 $\mu \mathrm{g} / \mathrm{side}$ ) into the PVN and BNST, but not VTA or locus 


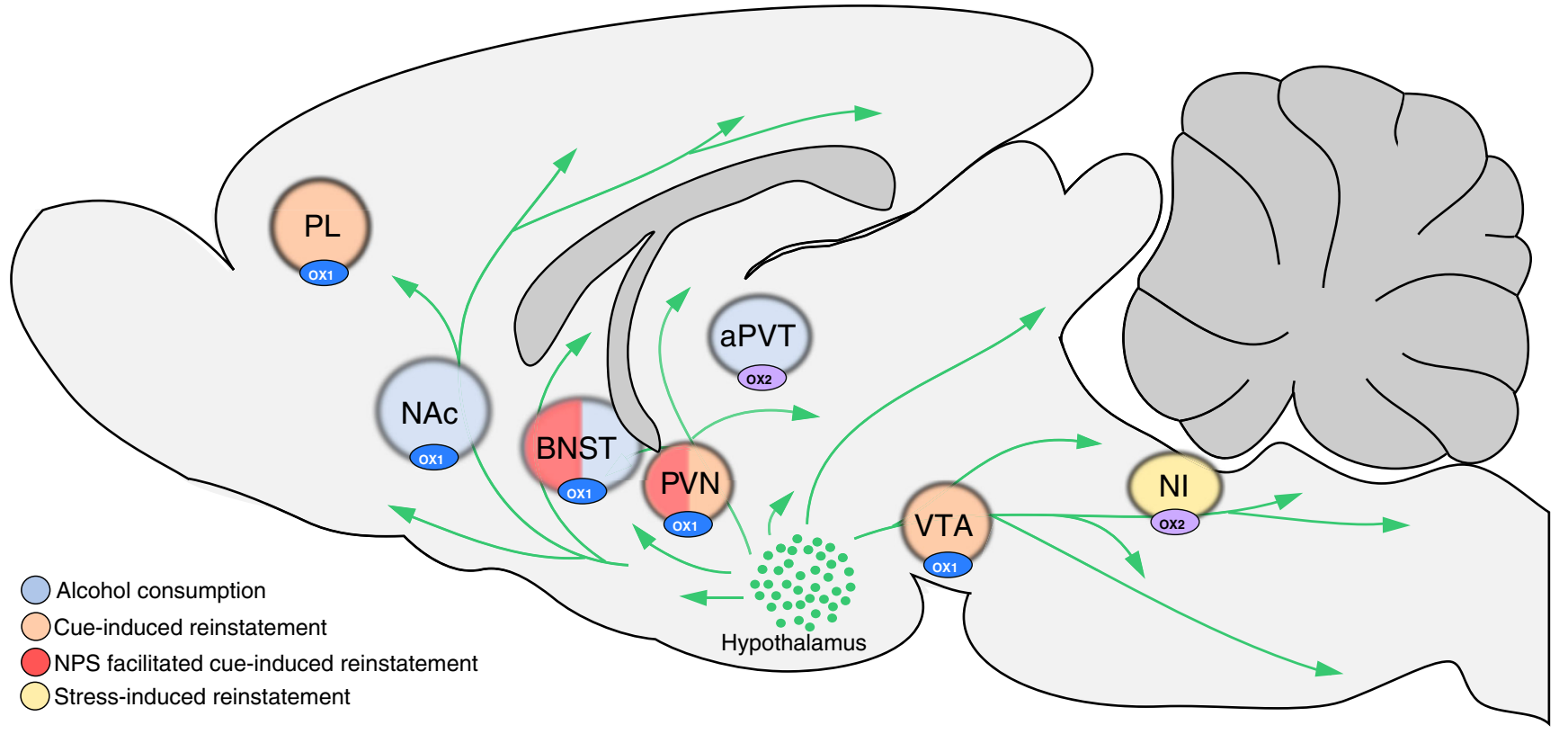

Fig. 1 Loci-specific role of $\mathrm{OX}_{1 / 2}$ receptor signaling in alcohol seeking. Orexin $(O X)$ neurons (green) in the hypothalamus send projections throughout the neuraxis, including regions where OX signaling has been implicated in different aspects of alcohol seeking. $\mathrm{OX}_{1}$ receptor antagonism in the nucleus accumbens $(N A C)$ and bed nucleus of the stria terminalis $(B N S T)$ and $\mathrm{OX}_{2}$ receptor antagonism in the anterior periventricular thalamus ( $a P V T)$ reduce alcohol consumption (blue).

coeruleus (LC) of male Wistar rats attenuated NPS-facilitated $(0.25 \mathrm{nmol} / \mathrm{side})$ cue-induced reinstatement of alcohol seeking. Contrary to previous studies, SB-334867 (5 $\mu \mathrm{g})$ microinjected into the VTA alone did not attenuate cueinduced alcohol seeking in Wistar rats.

Using unilateral injections of a retrograde tracer, the authors showed that the PVN and BNST receive OX innervation. While OX-A afferents to the PVN innervate both ipsilateral and contralateral hemispheres, OX-A projections to the BNST preferentially innervate the contralateral hemisphere. This suggests distinct OX projections are recruited following NPS stimulation and show the involvement of multiple brain regions acting in unison to mediate this behavior. To confirm the involvement of these regions in OX-mediated cue-induced reinstatement of alcohol seeking, the authors microinjected OX-A ( $3 \mathrm{nmol})$ intra-BNST or intra-PVN and found an enhancement in alcohol seeking but to a lesser degree than the intra-LH NPS microinjection. This suggests that a more robust cue-induced reinstatement of alcohol seeking is reliant on the activation of both the LH-BNST and LH-PVN pathways [60].

While comparatively little research has focused on the involvement of OX in stress-induced reinstatement of alcohol seeking, our lab has recently implicated $\mathrm{OX}_{2}$ signaling within a small pontine brain region, the nucleus incertus (NI). Microinjections of the $\mathrm{OX}_{2}$ receptor antagonist (TCS-OX2$29,100 \mu \mathrm{g} /$ side) but not $\mathrm{OX}_{1}$ receptor antagonist (SB-334867, $3 \mu \mathrm{g} / \mathrm{side}$ ) in the NI attenuated yohimbine-induced
$\mathrm{OX}_{1}$ receptor antagonism in the prelimbic cortex $(P L)$, paraventricular nucleus of the hypothalamus $(P V N)$ and ventral tegmental area (VTA) reduce cue-induced reinstatement of alcohol seeking (orange), and $\mathrm{OX}_{1}$ receptor antagonism in the BNST and PVN attenuated neuropeptide $\mathrm{S}$ (NPS) facilitated cue-induced reinstatement of alcohol seeking (red). $\mathrm{OX}_{2}$ receptor antagonism in the nucleus incertus $(N I)$ reduced stress-induced reinstatement of alcohol seeking (yellow)

reinstatement of alcohol seeking in iP rats. In line with this, electrophysiology showed OX-A (600 nmol) increased NI neuron depolarization, which could be blocked by preincubation with TCS-OX2-29 $(10 \mu \mathrm{M})$ but not SB$334867(10 \mu \mathrm{M})[22]$. These results suggest the NI as another locus in the brain in where OX may contribute to relapse to alcohol seeking and is discussed in further detail below.

By targeting specific downstream regions in which OX may be mediating alcohol-seeking behaviors, we can build a broader understanding of the role of OX in reward-related behaviors. Within the last 3 years, research has shown the involvement of several brain regions facilitating OXmediated alcohol behaviors. These include the NAc [56], PL [59], PVN, BNST [60], NI [22], aPVT [28] and VTA (although variable results observed $[59,60])$. Furthermore, OX-mediated alcohol seeking is not only region specific, but also receptor specific [28, 22]. Although different aspects of alcohol consumption and seeking were examined, the studies discussed give insight into how the OX system orchestrates alcohol-related behaviors. Given the role of the OX system in feeding and consummatory behaviors, future studies are required to determine which loci are involved in specific aspects of alcohol (and other drugs/natural reward) seeking. This may allow for particular elements of addiction (such as relapse) to be targeted via the OX system without affecting both natural feeding and consumption processes and other important functions of the OX system. 


\section{OX and Other Peptide/Neuromodulatory Systems}

Apart from OX, a number of neuropeptides in the hypothalamus influence alcohol intake. Research into the way these peptide systems may interact to mediate alcohol-seeking behaviors has gained more traction in recent years. Building on previous work implicating the $\mathrm{OX}_{2}$ receptor within the aPVT in alcohol consumption [28], Barson and colleagues examined the interaction between OX and substance P (SP), which is highly expressed in the PVT [62]. The authors found that SP (5 nmol), infused into the aPVT stimulates alcohol consumption in an intermittent two-bottle choice paradigm similar to infusion of OX-A and OX-B (1 nmol). Intra-PVT injection of an NK1R antagonist attenuated alcohol consumption to a similar extent as the $\mathrm{OX}_{2}$ receptor antagonist. A close relationship exists between SP and OX, whereby local OX injection increased SP mRNA and peptide levels, specifically in the aPVT but not pPVT. Furthermore, OX-induced alcohol drinking was blocked by a local NK1R antagonist administered at a subthreshold dose. This suggests that SP in the aPVT mediates the stimulatory effect of OX on alcohol drinking. As with OX, this effect is site specific, with SP in the pPVT or dorsal third ventricle having no effect on alcohol drinking. Furthermore, it is alcohol specific, with SP in the aPVT reducing the drinking of sucrose and stimulating it in the pPVT. This suggests that natural reward consumption and alcohol-associated reward consumption are in part mediated by different subregions of the PVT.

Dopamine is a key neurotransmitter implicated in reward processing, including alcohol consumption [63, 64]. Dopamine D1 and D2 receptors are also expressed in the hypothalamus and activate OX neurons [65]. A recent study examined the role of dopamine D1 and D2 receptors in the $\mathrm{PeF} / \mathrm{LH}$ on alcohol consumption and neuropeptide expression following voluntary alcohol consumption. The D1 receptor agonist SKF81297 (5.4 nmol or $10.8 \mathrm{nmol} /$ side) bilaterally microinjected into the PeF/LH tended to increase alcohol consumption, while microinjection of the D1 receptor antagonist $\mathrm{SCH} 23390$ (15.4 nmol/side) caused a significant reduction in alcohol drinking behavior 1 and $2 \mathrm{~h}$ following infusion. Contrastingly, the D2 receptor agonist quinelorane dihydrochloride $(6.2 \mathrm{nmol} / \mathrm{side})$ decreased alcohol intake within $2 \mathrm{~h}$, whereas the D2 receptor antagonist sulpiride (23.4 nmol/side) stimulated the consumption of alcohol 1 and $2 \mathrm{~h}$ post injection. Water and food consumption were unaffected following microinjections [66]. These results show opposing functions for the dopamine (DA) receptor subtypes in the $\mathrm{PF} / \mathrm{LH}$ in controlling alcohol intake. The authors also examined the expression of $\mathrm{OX}$ and melanin-concentrating hormone $(\mathrm{MCH})$ mRNA in animals receiving vehicle, SKF81297 or quinelorane in the PF/LH. SKF81297 ( $10.8 \mathrm{nmol} /$ side) increased OX neuron density in the LH by $29 \%$ and $13 \%$ in the PeF, without altering MCH mRNA expression in the LH or ZI. Quinelorane $(6.2 \mathrm{nmol} / \mathrm{side})$ led to a $26 \%$ reduction in OX expression specifically in the $\mathrm{LH}$ but not in the PeF. Once again MCH mRNA density was unaffected by D2 receptor stimulation, both in the $\mathrm{LH}$ or the ZI [66]. These endogenous OX gene expression changes suggest a modulatory role for local OX-expressing neurons in mediating alcohol consumption. However, it is unlikely that this is a direct effect of DA on OX neurons, with little DA receptor mRNA expressed in LH/PFA neurons, and suggests that OX neurons may be trans-synaptically activated [65].

Another prominent subpopulation of LH neurons expresses $\mathrm{MCH}$, which are distinct from OX neurons. Prasad et al. [67] examined the involvement of $\mathrm{OX}$ and $\mathrm{MCH}$ on $\mathrm{ABA}$ renewal of alcohol seeking. [67]. Long-Evans rats were injected with an antisense morpholino $(0.6 \mathrm{nM})$, which knocked down $50 \%$ of $\mathrm{OX}$ protein expression in the $\mathrm{LH}$, without affecting $\mathrm{MCH}$ protein expression. At this dose $(0.6 \mathrm{nM})$, no changes in renewal were observed. A higher dose (1.2 nM) achieved a significant reduction in ABA renewal of alcohol seeking. However, while this dose significantly knocked down OX protein expression in the LH (again approx. $50 \%$ ), significant knockdown of $\mathrm{MCH}$ was also observed. Furthermore, the OX and $\mathrm{MCH}$ knockdown was adequate to inhibit reacquisition of alcoholic beer self-administration. This suggests that while the LH plays an important role in reacquisition and renewal of alcohol seeking, OX by itself may not be integral [67]. These findings are interesting, as the same authors have shown the recruitment of OX neurons following ABA renewal of alcohol seeking [21]; however, these results suggest this recruitment may not be contributing to the behavior. Methodological factors must be taken into account, since only $50 \%$ knockdown was achieved, suggesting that the activity of the remaining OX LH neurons may be sufficient to enable this response. Furthermore, the authors only examined expression of $\mathrm{OX}$ and $\mathrm{MCH}$; therefore, similar non-specific knockdown could have affected other hypothalamic peptides implicated in alcohol seeking such as neuropeptide Y (NPY), ENK and GAL.

Another peptide system that has been implicated in alcohol seeking is the relaxin-3/relaxin-like family peptide receptor 3 (RXFP3) system [25, 68]. This peptide is predominantly expressed in the pontine NI, and our lab has recently revealed a role for $\mathrm{OX}_{2}$ signaling in the $\mathrm{NI}$ in mediating stress-induced reinstatement of alcohol seeking [22]. This builds on studies that have shown OX receptor expression in the NI [69], a direct OX innervation of the NI and OX-induced excitation of relaxin-3 neurons [70], suggesting critical interplay between these neuropeptide systems. The relaxin- 3 system has been implicated in many neuromodulatory roles, including feeding, sleep/wake cycle, anxiety and stress (for review see [71]), which overlap with known modulatory roles of $\mathrm{OX}$. Previous studies have also shown a role for relaxin-3/ RXFP3 in alcohol self-administration and both cue- and stress-induced reinstatement [25]. With the knowledge that 
OX signaling is also involved in both alcohol consumption and reinstatement, the relaxin-3 system may be a possible mechanism of downstream modulation. Overall, the relaxin3 system provides another peptide system with which OX may interact to facilitate alcohol-related behaviors and could provide a useful therapeutic target.

To summarize, recent research has revealed several interactions in the OX and other peptide systems in alcohol consumption/seeking. These include potential upstream regulation of OX signaling by NPS [60] and DA [66] and downstream regulation of OX-mediated drinking via SP [62] and relaxin-3 [22]. The hypothalamic neuropeptides are likely to interact in multiple and complex ways in the process of modulating alcohol drinking. OX receptors are expressed on other hypothalamic neurons, including $\mathrm{MCH}$ in the $\mathrm{LH}$, ENK in the PVN and NPY in the arcuate nucleus (ARC) [72, 73], and may exert its effects via interactions with these and/or other peptide systems (see [74] for review). Of interest is the interaction of OX and dynorphin (DYN). Due to the opposing actions of OX and DYN on motivated behaviors, it is surprising that $95 \%$ of all OX neurons express DYN and they are released as cotransmitters under the same physiological conditions [75]. Corelease of $\mathrm{OX}$ is able to block the anti-reward effects of DYN via DA neurons, suggesting a dynamic balance between DYN and OX in facilitating reward [75]. The differential receptor distribution of the kappa-opioid receptor (KOR) and $\mathrm{OX}_{1 / 2}$ receptors throughout the brain may be a factor that influences downstream signaling and behavior. While OX expression is confined to a small part of the hypothalamus, DYN expression is more promiscuous. For example, not only is DYN colocalized with OX in neurons of the LH [76], it is also coexpressed with NPY in the ARC [77]. Therefore, the ability of OX to modulate drug-related behaviors might not be due to a reduction in OX signaling but a relative reduction in signaling in comparison to DYN. It would also be of interest to examine the interaction of $\mathrm{OX}$ and other hypothalamic peptides implicated in alcohol-related behaviors, such as NPY, MCH and CRF which all show reciprocal interactions [78, 79, 15].

\section{Conclusions}

In summary, over recent years, the OX alcohol field has steadily expanded knowledge of OX neuronal activation and expression, specific action of $\mathrm{OX}$ receptors in different aspects of alcohol seeking as well as building on loci-specific actions of OX receptors and interactions with other peptide systems. The recent publication of the crystal structure of the human $\mathrm{OX}_{2}$ receptor bound to suvorexant [80] will enable a more detailed understanding and importantly more directed design of pharmacological antagonists.

Ultimately, addictive behaviors are the result of cumulative responses to alcohol exposure, the genetic and epigenetic make-up of the individual and environmental factors over time. Understanding how environmental influences, such as adverse life events, moderate genetic risk is essential for the elucidation of mechanisms underlying AUDs. With the recent development of a zebrafish model of alcohol consumption, genetic studies may allow the characterization of single OX gene mutations on alcohol consumption and vulnerability to alcohol abuse [30]. A genome wide methylation study reported significantly increased promoter methylation at the OX gene during alcohol withdrawal [81], suggesting that epigenetic modifications secondary to alcohol intake, including DNA methylation, are associated with alcohol addiction, craving and withdrawal. Furthermore, the availability of transgenic mouse models including prepro-OX knockout [82], $\mathrm{OX}_{1}$ receptor, $\mathrm{OX}_{2}$ receptor [83] and double null $\mathrm{OX}_{1 / 2}$ receptor mutant mice [84] will allow examination of the impact of complete peptide or receptor deletion on AUDs. Indeed, studies examining morphine conditioned place preference (CPP) and sensitization have utilized transgenic mouse models [85]. However, these models lack the OX peptides, receptors or neurons from birth and thus do not replicate the typical onset of AUDs in humans and may develop compensatory mechanisms, reducing their behavioral relevance. Utilizing the OXtTA (tetracycline-controlled transcriptional activator) mice [86], a conditional OX knockout using diphtheria toxin A (DTA) expressed in OX neurons under the Tet-off system was recently reported [87]. This allows the control of OX neurodegeneration, which may be useful in determining the role of $\mathrm{OX}$ in different aspects of alcohol consumption and seeking. Furthermore, the OX-tTA mice can be bred with other lines with the tetracycline operator (TetO) knocked into specific gene promoter regions to induce specific overexpression in OX neurons [86]. The availability of OX-cre transgenic mice may also prove useful to allow specific manipulation of OX neurons with both optogenetic and chemogenetic approaches (see below) [88, 89]. Furthermore, reliable OX receptor reporter mouse lines are valuable in the examination of expression profiles and direct targeting of receptor-bearing neurons [90].

Other techniques such as optogenetics and chemogenetics (e.g. DREADDs, designer receptors exclusively activated by designer drugs) hold exciting possibilities in determining the behavioral functionality of specific OX neurons/projections. The recent development of a novel DREADD that is based on the Gi-coupled KOR receptor and its pharmacologically inert ligand salvinorin B [91] and its utility in studying brain circuitry involved in motivated behaviors in both mice [91] and rats [92] may provide the novel ability for bi-directional manipulation of $\mathrm{OX}$ neurons. Although original muscarinicbased DREADDs have been used to successfully manipulate OX neurons [93, 89], prior to the development of this KOR DREADD (KORD), the ability to inhibit or activate neuronal activity in the same animal was prevented due to the same 
ligand clozapine- $N$-oxide (CNO) activating multiple muscarinic receptor DREADDs. KORDs can be used in combination with the original muscarinic-based DREADDs to permit bi-directional control over specific neural projections. Furthermore, using dual virus manipulations, it is possible to isolate a specific neuronal pathway and determine its role in motivation-related behaviors [94]. Using these and other developing techniques, the ability to precisely modulate the OX system and determine specific roles is possible.

While a great deal is known about the OX system in animal models of alcohol consumption and seeking, the true test will come in human clinical trials. The availability of FDA approved DORA suvorexant and the current phase 2 clinical trial assessing its efficacy in reducing anxiety and cocaine use may spur further trials. Collectively, the wealth of knowledge we have obtained about the neurobiology of the orexin system highlights the therapeutic potential of targeting this neuropeptide to treat AUDs.

\section{Compliance with Ethical Standards}

Conflict of Interest LCW is supported by an Australian Postgraduate Scholarship; SSC was supported by a University of Melbourne International Scholarship and the Alan and Elizabeth Finkel Award, and AJL is an NHMRC fellow (1020737) and is supported by project grant 1079893 for this research. We also acknowledge the Victorian Government's Operational Infrastructure Support Program. LCW, SSC and AJL report no conflicts of interest.

Human and Animal Rights and Informed Consent All reported studies/experiments with human or animal subjects performed by the authors have been previously published and complied with all applicable ethical standards (including the Helsinki Declaration and its amendments, institutional/national research committee standards and international/national/institutional guidelines).

\section{References}

1. World Health Organization. Causes of death 2008: Data sources and methods. In: Department of Health Statistics and Informatics, editor.2011.

2. Rehm J, Mathers C, Popova S, Thavorncharoensap M, Teerawattananon Y, Patra J. Global burden of disease and injury and economic cost attributable to alcohol use and alcohol-use disorders. Lancet. 2009;373(9682):2223-33.

3. Anton RF. Pharmacologic approaches to the management of alcoholism. J Clin Psychiatry. 2001;62(Suppl 20):11-7.

4. Cowen MS, Chen F, Lawrence AJ. Neuropeptides: implications for alcoholism. J Neurochem. 2004;89(2):273-85.

5. Jupp B, Lawrence AJ. New horizons for therapeutics in drug and alcohol abuse. Pharmacol Ther. 2010;125(1):138-68.

6. Litten RZ, Wilford BB, Falk DE, Ryan ML, Fertig JB. Potential medications for the treatment of alcohol use disorder: an evaluation of clinical efficacy and safety. Subst Abus. 2016;37(2):286-98.
7. Khoo SY, Brown RM. Orexin/hypocretin based pharmacotherapies for the treatment of addiction: DORA or SORA? CNS Drugs. 2014;28(8):713-30.

8. De Lecea L, Kilduff T, Peyron C, Gao X-B, Foye P, Danielson P, et al. The hypocretins: hypothalamus-specific peptides with neuroexcitatory activity. Proc Natl Acad Sci U S A. 1998;95(1): $322-7$.

9. Sakurai T, Amemiya A, Ishii M, Matsuzaki I, Chemelli RM, Tanaka $\mathrm{H}$, et al. Orexins and orexin receptors: a family of hypothalamic neuropeptides and $\mathrm{G}$ protein-coupled receptors that regulate feeding behavior. Cell. 1998;92(4):573-85.

10. Ammoun S, Holmqvist T, Shariatmadari R, Oonk HB, Detheux M, Parmentier $M$, et al. Distinct recognition of OX1 and OX2Receptors by orexin peptides. J Pharm Expl Ther. 2003;305(2):507-14.

11. Matsuki T, Sakurai T. Orexins and orexin receptors: from molecules to integrative physiology. Results Probl Cell Differ. 2008;46:27-55.

12. Kukkonen JP, Leonard CS. Orexin/hypocretin receptor signalling cascades. Br J Pharmacol. 2014;171(2):314-31.

13. Fadel J, Deutch AY. Anatomical substrates of orexin-dopamine interactions: lateral hypothalamic projections to the ventral tegmental area. Neuroscience. 2002;111(2):379-87.

14. Peyron C, Tighe DK, Van Den Pol AN, De Lecea L, Heller HC, Sutcliffe JG, et al. Neurons containing hypocretin (orexin) project to multiple neuronal systems. J Neurosci. 1998;18(23):999610015.

15. Winsky-Sommerer R, Boutrel B, De Lecea L. The role of the hypocretinergic system in the integration of networks that dictate the states of arousal. Drug News Perspect. 2003;16(8):504-12.

16. Harris GC, Wimmer M, Aston-Jones G. A role for lateral hypothalamic orexin neurons in reward seeking. Nature. 2005;437(7058): 556-9.

17. Boutrel B, Kenny PJ, Specio SE, Martin-Fardon R, Markou A, Koob GF, et al. Role for hypocretin in mediating stress-induced reinstatement of cocaine-seeking behavior. Proc Natl Acad Sci U S A. 2005;102(52):19168-73.

18. Lawrence AJ, Cowen MS, Yang HJ, Chen F, Oldfield B. The orexin system regulates alcohol-seeking in rats. Br J Pharmacol. 2006;148(6):752-9.

19. Chen YW, Barson JR, Chen A, Hoebel BG, Leibowitz SF. Hypothalamic peptides controlling alcohol intake: differential effects on microstructure of drinking bouts. Alcohol. 2014;48(7): 657-64.

20. Moorman DE, James MH, Kilroy EA, Aston-Jones G. Orexin/ hypocretin neuron activation is correlated with alcohol seeking and preference in a topographically specific manner. Eur J Neurosci. 2016;43(5):710-20.

21. Hamlin AS, Newby J, McNally GP. The neural correlates and role of D1 dopamine receptors in renewal of extinguished alcohol-seeking. Neuroscience. 2007;146(2):525-36.

22. Kastman HE, Blasiak A, Walker LC, Siwiec M, Krstew EV, Gundlach AL, Lawrence AJ. Nucleus incertus orexin2 receptors mediate alcohol seeking in rats. Neuropharmacology. 2016;110: 82-91.

23. Richards JK, Simms JA, Steensland P, Taha SA, Borgland SL, Bonci A, et al. Inhibition of orexin-1/hypocretin-1 receptors inhibits yohimbine-induced reinstatement of ethanol and sucrose seeking in Long-Evans rats. Psychopharmacology. 2008;199(1): 109-17.

24. Sharma R, Sahota P, Thakkar MM. Role of adenosine and the orexinergic perifornical hypothalamus in sleep-promoting effects of ethanol. Sleep. 2014;37(3):525-33.

25. Ryan PJ, Kastman HE, Krstew EV, Rosengren KJ, Hossain MA, Churilov L, et al. Relaxin-3/RXFP3 system regulates alcohol-seeking. Proc Natl Acad Sci U S A. 2013;110(51):20789-94. 
26. Furlong TM, Vianna DM, Liu L, Carrive P. Hypocretin/orexin contributes to the expression of some but not all forms of stress and arousal. Eur J Neurosci. 2009;30(8):1603-14.

27. Olney JJ, Navarro M, Thiele TE. Binge-like consumption of ethanol and other salient reinforcers is blocked by orexin-1 receptor inhibition and leads to a reduction of hypothalamic orexin immunoreactivity. Alcohol Clin Exp Res. 2015;39(1):21-9.

28. Barson JR, Ho HT, Leibowitz SF. Anterior thalamic paraventricular nucleus is involved in intermittent access ethanol drinking: role of orexin receptor 2. Addict Biol. 2015;20(3):469-81.

29. Carvajal F, Alcaraz-Iborra M, Lerma-Cabrera JM, Valor LM, de la Fuente L, Sanchez-Amate Mdel C, et al. Orexin receptor 1 signaling contributes to ethanol binge-like drinking: pharmacological and molecular evidence. Behav Brain Res. 2015;287:230-7.

30. Sterling ME, Karatayev O, Chang GQ, Algava DB, Leibowitz SF. Model of voluntary ethanol intake in zebrafish: effect on behavior and hypothalamic orexigenic peptides. Behav Brain Res. 2015;278: 29-39.

31. Sterling ME, Chang GQ, Karatayev O, Chang SY, Leibowitz SF. Effects of embryonic ethanol exposure at low doses on neuronal development, voluntary ethanol consumption and related behaviors in larval and adult zebrafish: role of hypothalamic orexigenic peptides. Behav Brain Res. 2016;304:125-38.

32. Ziolkowski M, Czarnecki D, Budzynski J, Rosinska Z, Zekanowska E, Goralczyk B. Orexin in patients with alcohol dependence treated for relapse prevention: a pilot study. Alcohol Alcohol. 2016; 51(4):416-21.

33. Mahler SV, Moorman DE, Smith RJ, James MH, Aston-Jones G. Motivational activation: a unifying hypothesis of orexin/hypocretin function. Nat Neurosci. 2014;17(10):1298-303.

34. Anderson RI, Becker HC, Adams BL, Jesudason CD, Rorick-Kehn LM. Orexin-1 and orexin-2 receptor antagonists reduce ethanol self-administration in high-drinking rodent models. Front Neurosci. 2014;8:33.

35. McElhinny Jr CJ, Lewin AH, Mascarella SW, Runyon S, Brieaddy L, Carroll FI. Hydrolytic instability of the important orexin 1 receptor antagonist SB-334867: possible confounding effects on in vivo and in vitro studies. Bioorg Med Chem Lett. 2012;22(21):6661-4.

36. Gotter AL, Roecker AJ, Hargreaves R, Coleman PJ, Winrow CJ, Renger JJ. Orexin receptors as therapeutic drug targets. Prog Brain Res. 2012;198:163-88.

37. Lopez MF, Moorman DE, Aston-Jones G, Becker HC. The highly selective orexin/hypocretin 1 receptor antagonist GSK1059865 potently reduces ethanol drinking in ethanol dependent mice. Brain Res. 2016;1636:74-80.

38. Lei K, Wegner SA, Yu J-H, Hopf FW. Orexin-1 receptor blockade suppresses compulsive-like alcohol drinking in mice. Neuropharmacology. 2016;110(PtA):431-37.

39. Moorman DE, Aston-Jones G. Orexin-1 receptor antagonism decreases ethanol consumption and preference selectively in highethanol-preferring Sprague-Dawley rats. Alcohol. 2009;43(5): 379-86.

40. Lu XY, Bagnol D, Burke S, Akil H, Watson SJ. Differential distribution and regulation of $\mathrm{OX} 1$ and $\mathrm{OX} 2$ orexin/hypocretin receptor messenger RNA in the brain upon fasting. Horm Behav. 2000;37(4):335-44.

41. Jupp B, Krivdic B, Krstew E, Lawrence AJ. The orexin 1 receptor antagonist SB-334867 dissociates the motivational properties of alcohol and sucrose in rats. Brain Res. 2011;1391:54-9.

42. Zhou L, Ghee SM, Chan C, Lin L, Cameron MD, Kenny PJ, et al. Orexin-1 receptor mediation of cocaine seeking in male and female rats. J Pharmacol Exp Ther. 2012;340(3):801-9.

43. Thorpe AJ, Cleary JP, Levine AS, Kotz CM. Centrally administered orexin A increases motivation for sweet pellets in rats. Psychopharmacology. 2005;182(1):75-83.
44. Morairty SR, Revel FG, Malherbe P, Moreau JL, Valladao D, Wettstein JG, et al. Dual hypocretin receptor antagonism is more effective for sleep promotion than antagonism of either receptor alone. PLoS One. 2012;7(7):e39131.

45. Russell SH, Small CJ, Kennedy AR, Stanley SA, Seth A, Murphy $\mathrm{KG}$, et al. Orexin A interactions in the hypothalamo-pituitary gonadal axis. Endocrinology. 2001;142(12):5294-302.

46. Cox CD, Breslin MJ, Whitman DB, Schreier JD, McGaughey GB, Bogusky MJ, et al. Discovery of the dual orexin receptor antagonist [(7R)-4-(5-chloro-1,3-benzoxazol-2-yl)-7-methyl-1,4-diazepan-1yl][5-methyl-2-(2H-1,2,3-triazol-2-yl)phenyl]methanone (MK4305) for the treatment of insomnia. J Med Chem. 2010;53(14): 5320-32.

47. Muschamp JW, Dominguez JM, Sato SM, Shen RY, Hull EM. A role for hypocretin (orexin) in male sexual behavior. J Neurosci. 2007;27(11):2837-45.

48. Sun H, Yee KL, Gill S, Liu W, Li X, Panebianco D, et al. Psychomotor effects, pharmacokinetics and safety of the orexin receptor antagonist suvorexant administered in combination with alcohol in healthy subjects. J Psychopharmacol. 2015;0269881115609015.

49. Steiner MA, Lecourt H, Jenck F. The dual orexin receptor antagonist almorexant, alone and in combination with morphine, cocaine and amphetamine, on conditioned place preference and locomotor sensitization in the rat. Int J Neuropsychopharmacol. 2013;16(2): 417-32.

50. Zhou L, Smith RJ, Do PH, Aston-Jones G, See RE. Repeated orexin 1 receptor antagonism effects on cocaine seeking in rats. Neuropharmacology. 2012;63(7):1201-7.

51. Brundin L, Björkqvist M, Petersén Å, Träskman-Bendz L. Reduced orexin levels in the cerebrospinal fluid of suicidal patients with major depressive disorder. Euro Neuropsychopharmacol. 2007;17(9):573-9.

52. Brundin L, Björkqvist M, Träskman-Bendz L, Petersén Å. Increased orexin levels in the cerebrospinal fluid the first year after a suicide attempt. J Affect Disord. 2009;113(1):179-82.

53. Lutter M, Krishnan V, Russo SJ, Jung S, McClung CA, Nestler EJ. Orexin signaling mediates the antidepressant-like effect of calorie restriction. J Neurosci. 2008;28(12):3071-5.

54. Mayannavar S, Rashmi KS, Rao YD, Yadav S, Ganaraja B. Effect of orexin-a infusion in to the nucleus accumbens on consummatory behaviour and alcohol preference in male Wistar rats. Indian $\mathrm{J}$ Physiol Pharmacol. 2014;58(4):319-26.

55. Brown RM, Khoo SY-S, Lawrence AJ. Central orexin (hypocretin) 2 receptor antagonism reduces ethanol self-administration, but not cue-conditioned ethanol-seeking, in ethanol-preferring rats. Int $\mathrm{J}$ Neuropsychopharmacol. 2013;16(09):2067-79.

56. Mayannavar S, Rashmi KS, Rao YD, Yadav S, Ganaraja B. Effect of orexin A antagonist (SB-334867) infusion into the nucleus accumbens on consummatory behavior and alcohol preference in Wistar rats. Indian J Pharmacol. 2016;48(1):53-8.

57. Hamlin AS, Clemens KJ, Choi EA, McNally GP. Paraventricular thalamus mediates context-induced reinstatement (renewal) of extinguished reward seeking. Euro J Neurosci. 2009;29(4):802-12.

58. Marcus JN, Aschkenasi CJ, Lee CE, Chemelli RM, Saper CB, Yanagisawa $\mathrm{M}$, et al. Differential expression of orexin receptors 1 and 2 in the rat brain. J Comp Neurol. 2001;435(1):6-25.

59. Brown RM, Kim AK, Khoo SY, Kim JH, Jupp B, Lawrence AJ. Orexin-1 receptor signalling in the prelimbic cortex and ventral tegmental area regulates cue-induced reinstatement of ethanolseeking in iP rats. Addict Biol. 2016;21(3):603-12.

60. Ubaldi M, Giordano A, Severi I, Li H, Kallupi M, de Guglielmo G, et al. Activation of hypocretin-1/orexin-A neurons projecting to the bed nucleus of the stria terminalis and paraventricular nucleus is critical for reinstatement of alcohol seeking by neuropeptide S. Biol Psychiatry. 2016;79(6):452-62. 
61. Cannella N, Economidou D, Kallupi M, Stopponi S, Heilig M, Massi M, et al. Persistent increase of alcohol-seeking evoked by neuropeptide $\mathrm{S}$ : an effect mediated by the hypothalamic hypocretin system. Neuropsychopharmacology. 2009;34(9):2125-34.

62. Barson JR, Poon K, Ho HT, Alam MI, Sanzalone L, Leibowitz SF. Substance P in the anterior thalamic paraventricular nucleus: promotion of ethanol drinking in response to orexin from the hypothalamus. Addict Biol. 2015. doi:10.1111/adb.12288.

63. Liu X, Weiss F. Reversal of ethanol-seeking behavior by D1 and D2 antagonists in an animal model of relapse: differences in antagonist potency in previously ethanol-dependent versus nondependent rats. J Pharmacol Exp Ther. 2002;300(3):882-9.

64. Thanos PK, Katana JM, Ashby Jr CR, Michaelides M, Gardner EL, Heidbreder CA, et al. The selective dopamine D3 receptor antagonist SB-277011-A attenuates ethanol consumption in ethanol preferring $(\mathrm{P})$ and non-preferring (NP) rats. Pharmacol Biochem Behav. 2005;81(1):190-7.

65. Bubser M, Fadel JR, Jackson LL, Meador-Woodruff JH, Jing D, Deutch AY. Dopaminergic regulation of orexin neurons. Eur $\mathrm{J}$ Neurosci. 2005;21(11):2993-3001.

66. Chen YW, Morganstern I, Barson JR, Hoebel BG, Leibowitz SF. Differential role of D1 and D2 receptors in the perifornical lateral hypothalamus in controlling ethanol drinking and food intake: possible interaction with local orexin neurons. Alcohol Clin Exp Res. 2014;38(3):777-86.

67. Prasad AA, McNally GP. Effects of vivo morpholino knockdown of lateral hypothalamus orexin/hypocretin on renewal of alcohol seeking. PLoS One. 2014;9(10):e110385.

68. Walker AW, Smith CM, Chua BE, Krstew EV, Zhang C, Gundlach AL, et al. Relaxin-3 receptor (RXFP3) signalling mediates stressrelated alcohol preference in mice. PLoS One. 2015;10(4): e0122504.

69. Greco MA, Shiromani PJ. Hypocretin receptor protein and mRNA expression in the dorsolateral pons of rats. Brain Res Mol Brain Res. 2001;88(1-2):176-82.

70. Blasiak A, Siwiec M, Grabowiecka A, Blasiak T, Czerw A, Blasiak E, et al. Excitatory orexinergic innervation of rat nucleus incertusimplications for ascending arousal, motivation and feeding control. Neuropharmacology. 2015;99:432-47.

71. Smith CM, Ryan PJ, Hosken IT, Ma S, Gundlach AL. Relaxin-3 systems in the brain-the first 10 years. J Chem Neuroanat. 2011;42(4):262-75.

72. Backberg M, Hervieu G, Wilson S, Meister B. Orexin receptor-1 (OX-R1) immunoreactivity in chemically identified neurons of the hypothalamus: focus on orexin targets involved in control of food and water intake. Eur J Neurosci. 2002;15(2):315-28.

73. Barson JR, Chang GQ, Poon K, Morganstern I, Leibowitz SF. Galanin and the orexin 2 receptor as possible regulators of enkephalin in the paraventricular nucleus of the hypothalamus: relation to dietary fat. Neuroscience. 2011;193:10-20.

74. Barson JR, Leibowitz SF. Hypothalamic neuropeptide signaling in alcohol addiction. Prog Neuro-Psychopharmacol Biol Psychiatry. 2016;65:321-9.

75. Muschamp JW, Hollander JA, Thompson JL, Voren G, Hassinger LC, Onvani S, et al. Hypocretin (orexin) facilitates reward by attenuating the antireward effects of its cotransmitter dynorphin in ventral tegmental area. Proc Natl Acad Sci U S A. 2014;111(16): E1648-55.

76. Chou TC, Lee CE, Lu J, Elmquist JK, Hara J, Willie JT, et al. Orexin (hypocretin) neurons contain dynorphin. J Neurosci. 2001;21(19):Rc168.

77. Lin S, Boey D, Lee N, Schwarzer C, Sainsbury A, Herzog H. Distribution of prodynorphin mRNA and its interaction with the NPY system in the mouse brain. Neuropeptides. 2006;40(2):115-23.

78. Guan JL, Uehara K, Lu S, Wang QP, Funahashi H, Sakurai T, et al. Reciprocal synaptic relationships between orexin- and melanin- concentrating hormone-containing neurons in the rat lateral hypothalamus: a novel circuit implicated in feeding regulation. Int J Obes Relat Metab Disord. 2002;26(12):1523-32.

79. Muroya S, Funahashi H, Yamanaka A, Kohno D, Uramura K, Nambu T, et al. Orexins (hypocretins) directly interact with neuropeptide Y, POMC and glucose-responsive neurons to regulate $\mathrm{Ca}$ $2+$ signaling in a reciprocal manner to leptin: orexigenic neuronal pathways in the mediobasal hypothalamus. Eur J Neurosci. 2004;19(6):1524-34.

80. Yin J, Mobarec JC, Kolb P, Rosenbaum DM. Crystal structure of the human OX2 orexin receptor bound to the insomnia drug suvorexant. Nature. 2015;519(7542):247-50.

81. Bayerlein K, Kraus T, Leinonen I, Pilniok D, Rotter A, Hofner B, et al. Orexin A expression and promoter methylation in patients with alcohol dependence comparing acute and protracted withdrawal. Alcohol. 2011;45(6):541-7.

82. Chemelli RM, Willie JT, Sinton CM, Elmquist JK, Scammell T, Lee $\mathrm{C}$, et al. Narcolepsy in orexin knockout mice: molecular genetics of sleep regulation. Cell. 1999;98(4):437-51.

83. Willie JT, Chemelli RM, Sinton CM, Tokita S, Williams SC, Kisanuki YY, et al. Distinct narcolepsy syndromes in orexin receptor-2 and orexin null mice: molecular genetic dissection of non-REM and REM sleep regulatory processes. Neuron. 2003;38(5):715-30.

84. Kalogiannis M, Hsu E, Willie JT, Chemelli RM, Kisanuki YY, Yanagisawa M, et al. Cholinergic modulation of narcoleptic attacks in double orexin receptor knockout mice. PLoS One. 2011;6(4): e18697.

85. Sharf R, Guarnieri DJ, Taylor JR, DiLeone RJ. Orexin mediates morphine place preference, but not morphine-induced hyperactivity or sensitization. Brain Res. 2010;1317:24-32.

86. Tabuchi S, Tsunematsu T, Kilduff TS, Sugio S, Xu M, Tanaka KF, et al. Influence of inhibitory serotonergic inputs to orexin/ hypocretin neurons on the diurnal rhythm of sleep and wakefulness. Sleep. 2013;36(9):1391.

87. Tabuchi S, Tsunematsu T, Black SW, Tominaga M, Maruyama M, Takagi K, et al. Conditional ablation of orexin/hypocretin neurons: a new mouse model for the study of narcolepsy and orexin system function. J Neurosci. 2014;34(19):6495-509.

88. Matsuki T, Nomiyama M, Takahira H, Hirashima N, Kunita $\mathrm{S}$, Takahashi $\mathrm{S}$, et al. Selective loss of GABA(B) receptors in orexin-producing neurons results in disrupted sleep/ wakefulness architecture. Proc Natl Acad Sci U S A. 2009;106(11):4459-64.

89. Sasaki K, Suzuki M, Mieda M, Tsujino N, Roth B, Sakurai T. Pharmacogenetic modulation of orexin neurons alters sleep/ wakefulness states in mice. PLoS One. 2011;6(5):e20360.

90. Ch'ng SS, Lawrence AJ. Distribution of the orexin-1 receptor (OX1R) in the mouse forebrain and rostral brainstem: a characterisation of OX1R-eGFP mice. J Chem Neuroanat. 2015;66-67:1-9.

91. Vardy E, Robinson JE, Li C, Olsen RH, DiBerto JF, Giguere PM, et al. A new DREADD facilitates the multiplexed chemogenetic interrogation of behavior. Neuron. 2015;86(4):936-46.

92. Marchant NJ, Whitaker LR, Bossert JM, Harvey BK, Hope BT, Kaganovsky K. Behavioral and physiological effects of a novel kappa-opioid receptor-based DREADD in rats. Neuropsychopharmacology. 2016;41(2):402-9.

93. Inutsuka $\mathrm{A}$, Inui $\mathrm{A}$, Tabuchi $\mathrm{S}$, Tsunematsu $\mathrm{T}$, Lazarus $\mathrm{M}$, Yamanaka A. Concurrent and robust regulation of feeding behaviors and metabolism by orexin neurons. Neuropharmacology. 2014;85:451-60.

94. Boender AJ, de Jong JW, Boekhoudt L, Luijendijk MC, van der Plasse G, Adan RA. Combined use of the canine adenovirus-2 and DREADD-technology to activate specific neural pathways in vivo. PLoS One. 2014;9(4):e95392. 